Letter

\title{
Lagrangian Drifter to Identify Ocean Eddy Characteristics
}

\author{
Peter C. Chu *(D) and Chenwu Fan
}

Department of Oceanography, Naval Postgraduate School, Monterey, CA 93943, USA

* Correspondence: pcchu@nps.edu

Received: 18 October 2019; Accepted: 1 December 2019; Published: 5 December 2019

\begin{abstract}
Deterministic-stochastic empirical mode decomposition (EMD) is used to obtain lowfrequency (non-diffusive; i.e., background velocity) and high-frequency (diffusive; i.e., eddies) components from a Lagrangian drifter's trajectory. Eddy characteristics are determined from the time series of eddy trajectories from individual Lagrangian drifters such as eddy radius, eddy velocity, eddy Rossby number, and the eddy-current kinetic energy ratio. A long-term dataset of the Sound Fixing and Ranging (RAFOS) float time series obtained near the California coast by the Naval Postgraduate School from 1992 to 2004 at depth between 150 and $600 \mathrm{~m}$ is used as an example to demonstrate the capability of the deterministic-stochastic EMD.
\end{abstract}

Keywords: Lagrangian drifter; RAFOS floats; empirical mode decomposition (EMD); deterministicstochastic EMD; intrinsic mode function (IMF); eddy radial scale; eddy velocity scale; eddy Rossby number; eddy-current kinetic energy ratio

\section{Introduction}

A Lagrangian trajectory, $\mathbf{x}\left(t_{j}\right)=\left[x\left(t_{j}\right), y\left(t_{j}\right)\right]$, with $x$ in the zonal direction and $y$ in the meridional direction, can be separated into deterministic (low-frequency mode representing the background trajectory $\mathbf{x}_{\text {det }}\left(t_{j}\right)$ ) and stochastic (non-low-frequency mode representing the eddy trajectory, $\mathbf{x}_{s t o}(t)$ ),

$$
x\left(t_{j}\right)=x_{\text {det }}\left(t_{j}\right)+x_{\text {sto }}\left(t_{j}\right), y\left(t_{j}\right)=y_{\text {det }}\left(t_{j}\right)+y_{\text {sto }}\left(t_{j}\right), j=1,2, \ldots, J
$$

using the empirical mode decomposition (EMD) with the steepest ascending mode ratio, namely, the deterministic-stochastic EMD [1] and wavelet decomposition with two distinguished (deterministic and stochastic) phase spectra [2]. Here, $J$ is the total number of position points of the trajectory. The EMD is used to decompose a Lagrangian trajectory into a series of intrinsic mode functions (IMFs) with corresponding specific scales for each IMF. The EMD has two striking features: (1) the IMFs are solely determined by the data; and (2) the total number of IMFs is quite small, such as seven in Figure 2 of [1]. The wavelet is used to decompose a Lagrangian trajectory into a series of existing orthogonal basis functions. The total number of basis functions is usually large, such as 900 in Figure $4 b, c$ of [2]. Comparing the two methods, the deterministic-stochastic EMD is much simpler and more efficient than the wavelet.

The deterministic and stochastic velocities can be calculated from position vector (only showing the $x$ direction) with the first-order difference for the two end points,

$$
u_{s t o}\left(t_{1}\right)=\frac{x_{\text {sto }}\left(t_{2}\right)-x_{\text {sto }}\left(t_{1}\right)}{t_{2}-t_{1}}, u_{s t o}\left(t_{J}\right)=\frac{x_{s t o}\left(t_{J}\right)-x_{s t o}\left(t_{J-1}\right)}{t_{J}-t_{J-1}}
$$


and the central difference for the internal points,

$$
u_{s t o}\left(t_{j}\right)=\frac{x_{s t o}\left(t_{j+1}\right)-x_{s t o}\left(t_{j-1}\right)}{t_{j+1}-t_{j-1}}, j=2,3, \ldots, J-1
$$

Such Lagrangian-type decomposition changes the traditional approach (an ensemble of trajectories) of using $N$ drifters $\left[\mathbf{x}^{(\mathrm{n})}(t), n=1, \ldots, N\right]$ to get the background velocity (i.e., mean flow) and eddies from the Lagrangian trajectory data (i.e., the background velocity is the Eulerian mean from the $N$ drifters),

$$
\mathbf{U}(x, y, t)=\left\langle\left[\mathbf{u}^{(n)}(t)\right]\right\rangle,
$$

and the subtraction of $\mathbf{U}$ from the observed Lagrangian drifters leads to the "residue" velocities,

$$
\mathbf{u}^{(n) \prime}(x, y, t)=\frac{d \mathbf{x}^{(n)}(t)}{d t}-\mathbf{U}(x, y, t),
$$

which determines the eddy velocity. Here, the bracket represents an ensemble average in the defined geographic region. The velocities are calculated from Lagrangian trajectories using binned velocities with cubic splines [3], routine ocean data assimilation systems [4] and data analysis methods such as optimal interpolation [5] and optimal spectral decomposition (OSD) [6,7]. A formula was derived to link the Eulerian velocity at grid points to the Lagrangian trajectory [8].

The classical ensemble approach, Equation (5), requires a sufficiently large number of drifters deployed at the same time to determine the eddy velocity. Usually, very few drifters are (or even one drifter is) deployed in a region. It is difficult to compute the background (ensemble mean) velocity $\mathbf{U}(x, y, t)$, which makes the ensemble method hard to use. On the other hand, the EMD decomposes a Lagrangian trajectory into intrinsic mode functions (IMFs) in time domains regardless of their linearity, stationarity, and stochasticity [9-11]. It is also used to separate oceanic wave motion from turbulence [12]. For the same reason, it is difficult to compare the traditional ensemble method and the EMD method using observational data. Such a comparison could be carried out using numerically modeled ocean data. However, it is beyond the scope of this paper.

The deterministic-stochastic EMD was used to decompose single drifter trajectory data into background and eddy velocities from the same 54 shallow (about 300 dbar) Sound Fixing and Ranging (RAFOS) float trajectory data as in $[1,13,14]$. Figure 1 shows the decomposition of the Float-N073 with the red curve representing the trajectory $\mathbf{x}\left(t_{j}\right)$, a thick blue curve denoting the deterministic displacement $\mathbf{x}_{\text {det }}\left(t_{j}\right)$, and a thin blue curve in the lower panel referring to the stochastic displacement $\mathbf{x}_{s t o}\left(t_{j}\right)$. After the decomposition, we obtain the background velocity as well as characteristic parameters of the eddy, such as its radius, velocity, Rossby number, and background kinetic energy ratio. The rest of the paper is organized as follows. Sections 2 and 3 present the identified background velocity and eddy characteristic parameters for each RAFOS float along with their statistics for 54 RAFOS floats. Section 4 describes the temporal variability of the background and eddy characteristic parameters. Section 5 presents the results. 

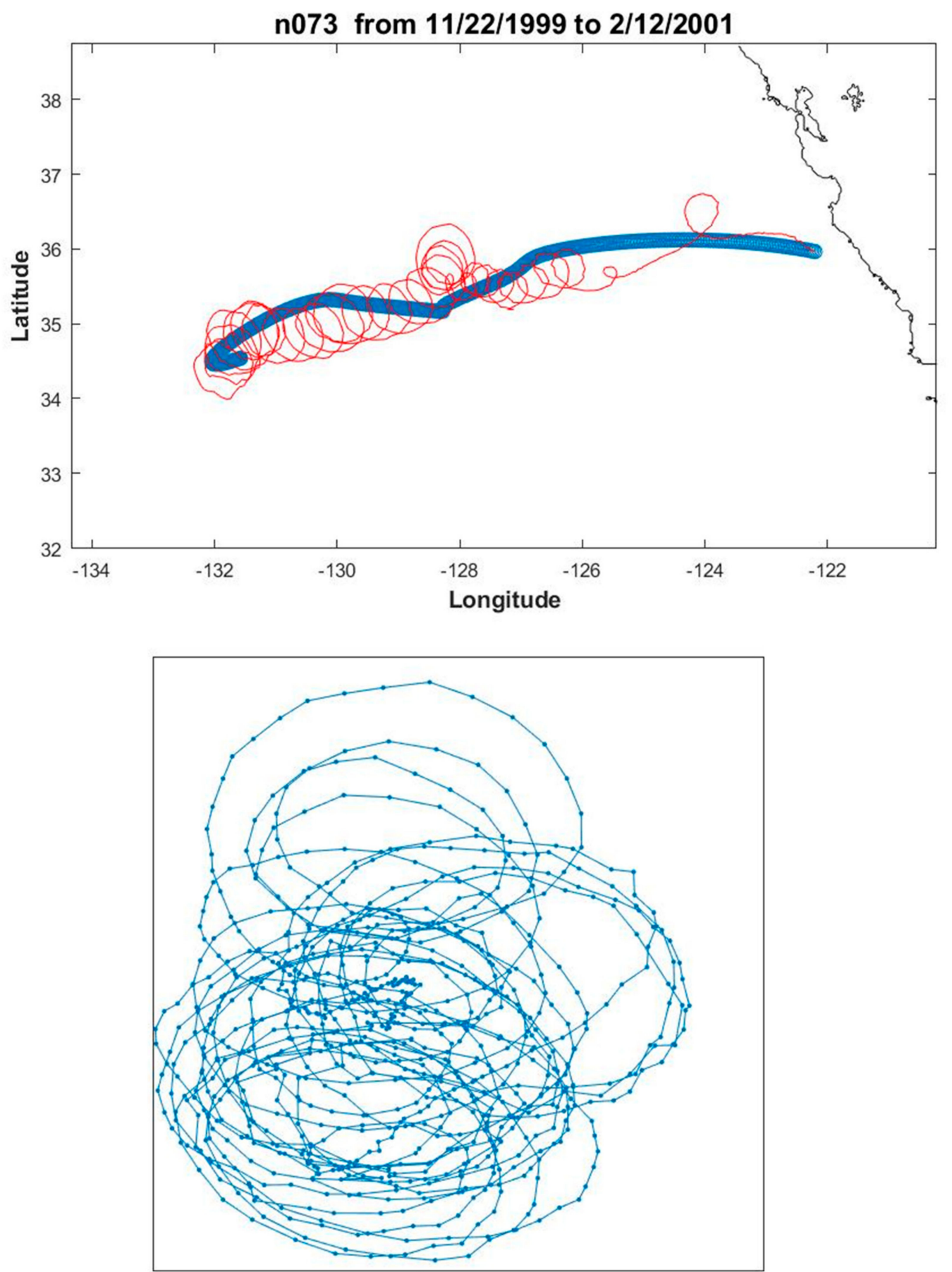

Figure 1. Deterministic-stochastic EMD on the RAFOS Float-N073: trajectory $\mathbf{x}\left(t_{j}\right)$ (red curve), deterministic displacement $\mathbf{x}_{\text {det }}\left(t_{j}\right)$ (thick blue curve) (above), and stochastic displacement $\mathbf{x}_{s t o}\left(t_{j}\right)$ (thin blue curve) (below).

\section{Eddy Characteristics Identified at Each Data Point of an Individual RAFOS Float}

After the deterministic and stochastic trajectories and velocities are obtained from an individual RAFOS float, the eddy characteristics can be easily identified at each data point. The eddy radius is defined by

$$
L_{e d d y}\left(t_{j}\right)=\sqrt{x_{\text {sto }}^{2}\left(t_{j}\right)+y_{\text {sto }}^{2}\left(t_{j}\right)} \text {. }
$$


The eddy swirling speed, $V_{\text {eddy }}\left(t_{j}\right)$, is defined by

$$
V_{\text {eddy }}\left(t_{j}\right)=\sqrt{\left(\frac{d x_{s t o}\left(t_{j}\right)}{d t}\right)^{2}+\left(\frac{d y_{s t o}\left(t_{j}\right)}{d t}\right)^{2}} .
$$

The eddy kinetic energy per unit mass $(E)$, eddy angular velocity $\left(\Omega_{\text {eddy }}\right)$, and eddy Rossby number $\left(R_{\text {eddy }}\right)$ are defined by

$$
E_{e d d y}\left(t_{j}\right)=\frac{V_{e d d y}^{2}\left(t_{j}\right)}{2}, \Omega_{e d d y}\left(t_{j}\right)=\frac{V_{\text {eddy }}\left(t_{j}\right)}{L_{e d d y}\left(t_{j}\right)}, R_{e d d y}\left(t_{j}\right) \equiv \frac{V_{\text {eddy }}\left(t_{j}\right)}{f L_{e d d y}\left(t_{j}\right)}=\frac{\Omega_{\text {eddy }}\left(t_{j}\right)}{f},
$$

where $f$ is the Coriolis parameter, which is evaluated at $40^{\circ} \mathrm{N}$, the central latitude of the 54 RAFOS floats (see Figure 1 in [1]). The background velocity (treated as current velocity) $V_{b}\left(t_{j}\right)$, is defined by

$$
V_{b}\left(t_{j}\right)=\sqrt{\left(\frac{d x_{\mathrm{det}}\left(t_{j}\right)}{d t}\right)^{2}+\left(\frac{d y_{\mathrm{det}}\left(t_{j}\right)}{d t}\right)^{2}} .
$$

The background kinetic energy per unit mass $\left(E_{b}\right)$ and eddy-background kinetic energy ratio $(r)$ are defined by

$$
E_{b}\left(t_{j}\right)=\frac{V_{b}^{2}\left(t_{j}\right)}{2}, r\left(t_{j}\right)=\frac{E_{e d d y}\left(t_{j}\right)}{E_{b}\left(t_{j}\right)}=\frac{V_{e d d y}^{2}\left(t_{j}\right)}{V_{b}^{2}\left(t_{j}\right)} .
$$

Due to an eddy's circular motion, the time series of $\left[x_{\text {sto }}\left(t_{j}\right), v_{\text {sto }}\left(t_{j}\right)\right]$ determines the types of eddy (cyclonic or anticyclonic),

$$
\begin{aligned}
& x_{\text {sto }}\left(t_{j}\right)>0 \rightarrow\left\{\begin{array}{c}
v_{\text {sto }}\left(t_{j}\right)>0 \rightarrow \text { cyclonic } \\
v_{\text {sto }}\left(t_{j}\right)<0 \rightarrow \text { anticyclonic }
\end{array}\right. \\
& x_{\text {sto }}\left(t_{j}\right)<0 \rightarrow\left\{\begin{array}{c}
v_{\text {sto }}\left(t_{j}\right)>0 \rightarrow \text { anticyclonic } \\
v_{\text {sto }}\left(t_{j}\right)<0 \rightarrow \text { cyclonic }
\end{array}\right.
\end{aligned}
$$

Table 1 shows the number of cyclonic/anticyclonic loops. For the RAFOS Float-N073, there are four cyclonic loops and 19 anticyclonic loops. Altogether, we identified 186 cyclonic (denoted by C) loops and 253 anticyclonic (denoted by AC) loops from 54 shallow RAFOS floats. Analysis on a similar RAFOS float dataset using the low-pass Butterworth filter was reported in [14]. The two datasets are not the same, although they are from the same data source [15]. There are no deep floats (deeper than 1000 dbar) in this study. Among the 54 shallow RAFOS floats in this paper, only 28 floats were included in [14]. Similar results were reached with more anticyclonic rotation than cyclonic rotation. However, the ratio between the anticyclonic to cyclonic loops was higher in [14] (2:1 in [14] vs 253:186 here).

\section{Statistics of Eddy Characteristic Parameters}

Histograms of the background velocity $\left(V_{b}\right)$ and eddy characteristic parameters such as radius $\left(L_{e d d y}\right)$, velocity $\left(V_{\text {eddy }}\right)$, Rossby number $\left(R_{\text {eddy }}\right)$, and eddy-background kinetic energy ratio $(r)$ are constructed from each loop of 54 RAFOS floats. All the histograms are non-symmetric, highly dispersive, and positively skewed (Figure 2). Earlier research [14] presented statistical characteristics for each float (not each observational loop). To compare with [14], we computed the root mean squares of background velocity, eddy velocity, and eddy radius along each float during its whole drifting period to get the corresponding scales $\left(\bar{V}_{b}, \bar{L}_{e d d y}, \bar{V}_{e d d y}\right)$. The eddy kinetic energy per unit mass $\left(\bar{E}_{e d d y}\right)$, 
eddy angular velocity scale $\left(\bar{\Omega}_{\text {eddy }}\right)$, eddy Rossby number $\left(\bar{R}_{\text {eddy }}\right)$, and energy ratio for each float are defined by

$$
\bar{E}_{e d d y}=\frac{\bar{V}_{e d d y}^{2}}{2}, \bar{\Omega}_{e d d y}=\frac{\bar{V}_{e d d y}}{\bar{L}_{e d d y}}, \bar{R}_{e d d y} \equiv \frac{\bar{V}_{e d d y}}{f \bar{L}_{e d d y}}=\frac{\bar{\Omega}_{e d d y}}{f}, \bar{r}=\frac{\bar{V}_{e d d y}^{2}}{\bar{V}_{b}^{2}} .
$$

The overall eddy kinetic energy is more than the background kinetic energy, with the ratio $\bar{r}$ having a mean of 1.78 , a standard deviation of 2.00, a skewness of 2.79, and a kurtosis 12.00 (Table 2). The eddy radial scale $\left(\bar{L}_{e d d y}\right)$ has a mean of $18.37 \mathrm{~km}$, a minimum of $1.12 \mathrm{~km}$, a maximum of $102.21 \mathrm{~km}$, a standard deviation of $21.33 \mathrm{~km}$, a skewness of 2.31, and a kurtosis of 8.50 . The eddy velocity scale $\left(\bar{V}_{\text {eddy }}\right)$ has a mean of $11.98 \mathrm{~cm} / \mathrm{s}$, a minimum of $2.72 \mathrm{~cm} / \mathrm{s}$, a maximum of $44.17 \mathrm{~cm} / \mathrm{s}$, a standard deviation of $8.65 \mathrm{~cm} / \mathrm{s}$, a skewness of 1.74 , and a kurtosis of 5.82. The results are compatible to [14] with "the median swirl speeds of $14 \mathrm{~cm} / \mathrm{s}$ for diameters of $59 \mathrm{~km}$ ".

Table 1. Identified number of cyclonic (denoted by C) and anticyclonic (denoted by AC) loops from 54 RAFOS floats with the floats marked by * not being included in [14]. Here \# denotes the number.

\begin{tabular}{|c|c|c|c|c|c|c|c|c|c|}
\hline Float & Buoy Days & dbar & \# C & \# AC & Float & Buoy Days & dbar & \# C & \# AC \\
\hline N002* & $8 / 12-9 / 11 / 92$ & 350 & 1 & 0 & N050* & 8/29/96-1/9/98 & 275 & 3 & 2 \\
\hline N003* & $8 / 12-9 / 11 / 92$ & 350 & 3 & 1 & N051 & 2/25/97-7/8/98 & 275 & 2 & 3 \\
\hline N004 * & 7/07-9/05/93 & 350 & 1 & 3 & N053* & 9/11/97-8/22/98 & 275 & 4 & 2 \\
\hline N005 & 9/03/93-1/01/94 & 350 & 3 & 4 & N055* & 9/11/97-8/22/98 & 275 & 1 & 1 \\
\hline N006 & $11 / 20 / 93-5 / 02 / 94$ & 350 & 0 & 1 & N062* & $4 / 29 / 98-6 / 25 / 99$ & 275 & 3 & 2 \\
\hline N007 & 7/07-9/05/93 & 350 & 2 & 7 & N063* & 5/17/98-7/12/99 & 275 & 0 & 2 \\
\hline N008 & 9/3-12/30/93 & 350 & 3 & 4 & N064* & 4/29/98-6/25/99 & 275 & 8 & 8 \\
\hline N010* & 9/3/93-1/1/04 & 350 & 2 & 2 & N065* & 4/29/98-6/24/99 & 275 & 6 & 4 \\
\hline N011 & $11 / 20 / 93-3 / 2 / 94$ & 350 & 0 & 6 & N066 & 10/27/98-12/23/99 & 275 & 1 & 2 \\
\hline N013 & $11 / 20 / 93-3 / 2 / 94$ & 350 & 0 & 4 & N067 & $10 / 27 / 98-12 / 23 / 99$ & 275 & 2 & 2 \\
\hline N014 & $1 / 11-4 / 23 / 94$ & 350 & 1 & 2 & N069 & 5/5/99-5/18/00 & 275 & 2 & 3 \\
\hline N019 & $4 / 25-11 / 11 / 94$ & 275 & 2 & 3 & N071 * & 5/5/99-5/18/00 & 275 & 4 & 6 \\
\hline N021 * & 5/19-6/10/94 & 275 & 12 & 16 & N072 & $11 / 21 / 99-2 / 12 / 01$ & 275 & 5 & 3 \\
\hline N022 * & 5/19-6/10/94 & 275 & 12 & 15 & N073 & $11 / 21 / 99-2 / 12 / 01$ & 275 & 4 & 19 \\
\hline N024* & $5 / 17-6 / 9 / 94$ & 275 & 13 & 27 & N075 & $11 / 21 / 99-2 / 12 / 01$ & 275 & 3 & 4 \\
\hline N026 & 8/22-12/30/94 & 290 & 3 & 5 & N080* & $7 / 26 / 00-9 / 23 / 01$ & 275 & 2 & 2 \\
\hline N028 & $8 / 12-12 / 19 / 94$ & 350 & 2 & 4 & N081* & $7 / 26 / 00-5 / 22 / 02$ & 275 & 3 & 2 \\
\hline N029* & $10 / 25 / 95-6 / 28 / 96$ & 300 & 2 & 2 & N082* & $7 / 26 / 00-9 / 24 / 01$ & 275 & 6 & 2 \\
\hline N030* & 5/18-6/10/94 & 275 & 14 & 19 & N083 & 9/11/00-12/29/01 & 275 & 4 & 7 \\
\hline N031 & $8 / 22-12 / 30 / 94$ & 290 & 0 & 4 & N084* & $9 / 11 / 00-7 / 9 / 02$ & 275 & 1 & 2 \\
\hline N032* & 8/7/95-10/6/96 & 300 & 3 & 1 & N085 & $9 / 11 / 00-7 / 9 / 02$ & 275 & 7 & 2 \\
\hline N033 & $8 / 12 / 94-5 / 10 / 95$ & 350 & 4 & 2 & N087* & $5 / 20 / 01-11 / 6 / 02$ & 275 & 2 & 2 \\
\hline N035* & $8 / 7 / 95-11 / 5 / 96$ & 300 & 1 & 3 & N088 & $5 / 20 / 01-7 / 28 / 03$ & 275 & 4 & 8 \\
\hline N039* & $7 / 29 / 96-12 / 10 / 97$ & 275 & 2 & 4 & N089 & $5 / 20 / 01-7 / 28 / 03$ & 275 & 4 & 1 \\
\hline N041 & 7/29/96-11/17/97 & 275 & 1 & 2 & N090 & $12 / 6 / 01-3 / 9 / 04$ & 275 & 4 & 4 \\
\hline N043 & 2/25-12/13/97 & 275 & 0 & 4 & N091 & $12 / 5 / 01-3 / 9 / 04$ & 275 & 3 & 7 \\
\hline \multirow[t]{2}{*}{ N048 } & 7/29/96-9/19/97 & 275 & 5 & 4 & N092* & $12 / 5 / 01-3 / 9 / 04$ & 275 & 6 & 2 \\
\hline & & & & & Total & & & 186 & 253 \\
\hline
\end{tabular}



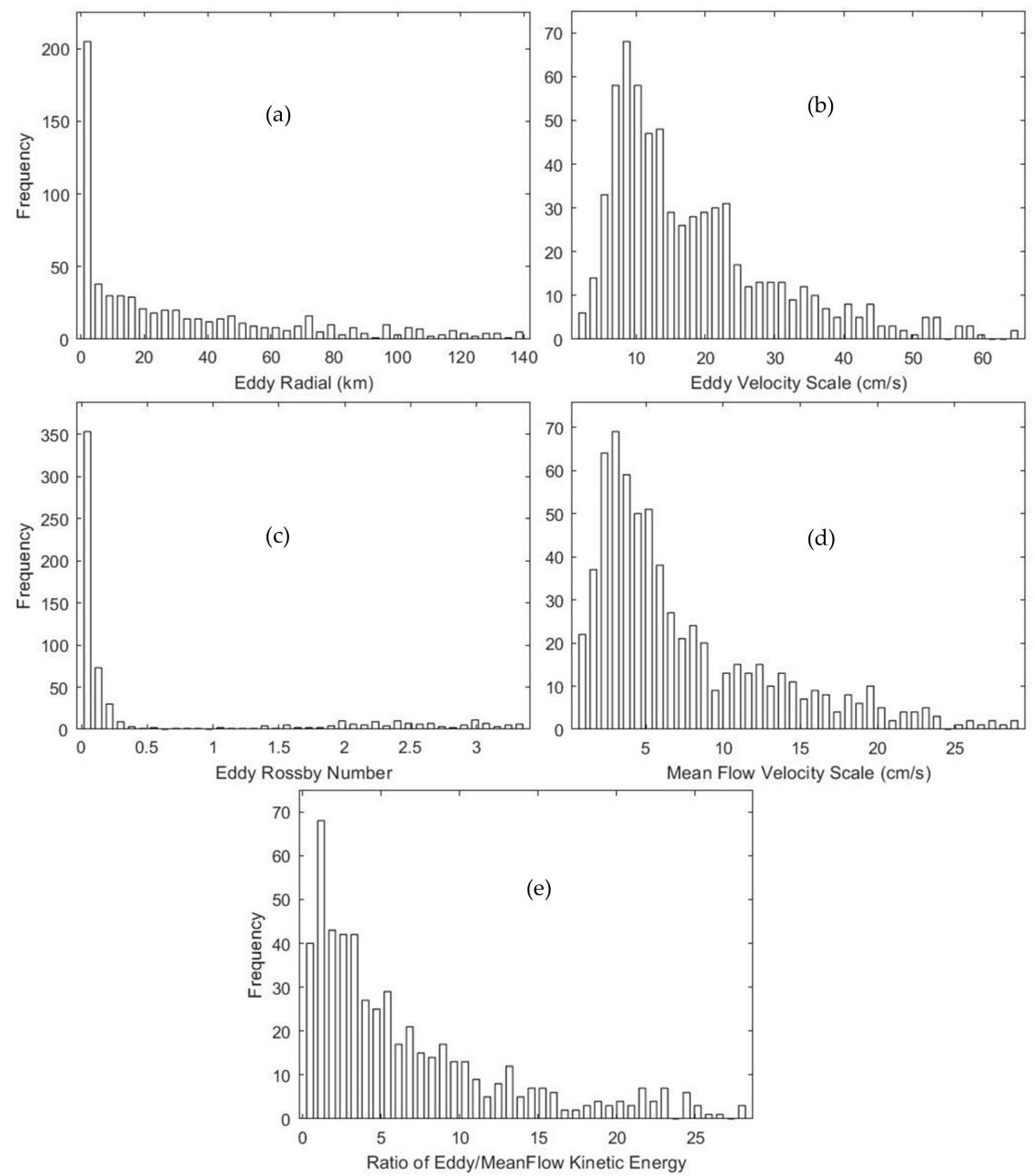

Figure 2. Histograms of current and eddy characteristic parameters identified for each loop from 54 shallow RAFOS floats: (a) eddy radius $(\mathrm{km}),(\mathbf{b})$ eddy velocity $(\mathrm{cm} / \mathrm{s}),(\mathbf{c})$ eddy Rossby number, (d) current velocity $(\mathrm{cm} / \mathrm{s})$, and (e) eddy and current kinetic energy ratio.

Table 2. Statistics of the eddy parameters identified for each float from a total of 54 shallow RAFOS floats (1992-2004).

\begin{tabular}{ccccccc}
\hline Parameter & Mean & Min & Max & Standard Deviation & Skewness & Kurtosis \\
\hline $\bar{L}_{\text {eddy }}(\mathrm{km})$ & 18.37 & 1.12 & 102.21 & 21.33 & 2.31 & 8.50 \\
$\bar{V}_{\text {eddy }}(\mathrm{cm} / \mathrm{s})$ & 11.98 & 2.72 & 44.17 & 8.65 & 1.74 & 5.82 \\
$\bar{V}_{b}(\mathrm{~cm} / \mathrm{s})$ & 10.04 & 4.19 & 31.59 & 5.39 & 2.38 & 8.96 \\
$\bar{R}_{\text {eddy }}$ & 0.35 & 0.01 & 3.99 & 0.86 & 3.34 & 12.90 \\
$\bar{r}$ & 1.78 & 0.13 & 11.19 & 2.00 & 2.79 & 12.00 \\
\hline
\end{tabular}

\section{Temporal Variability of Eddy Characteristic Parameters}

All the identified eddy and background parameters $\left(\bar{L}_{e d d y}, \bar{V}_{\text {eddy }}, \bar{R}_{\text {eddy }}, \bar{V}_{b}, \bar{r}\right)$ have evident temporal variability. Large dispersion is found in $\bar{L}_{\text {eddy }}$ before August 1998 from $1.12 \mathrm{~km}$ (7 July-5 September 1993 , N007) to $102.21 \mathrm{~km}$ (25 February 1997-8 July 1998, N051). Small dispersion in $\bar{L}_{e d d y}$ is found after August 1998 with a maximum of $36.53 \mathrm{~km}$ (21 November 1999-12 February 2001, N073) (Figure 3a) and a minimum of 1.81 km (5 May 1999-18 May 2000, N069). There was a strong El Nino and Southern Oscillation (ENSO) event in the North Pacific in 1997-1998. The effect of the ENSO needs to be further investigated. Large dispersion is found in $\bar{V}_{\text {eddy }}$ before 1995 from $6.91 \mathrm{~cm} / \mathrm{s}$ (7 July-5 September 1993, N007) to $44.17 \mathrm{~cm} / \mathrm{s}$ (19 May-10 June 1994, N021). Small dispersion is found after December 1994, with a maximum of $19.56 \mathrm{~cm} / \mathrm{s}$ (21 November 1999-12 February 2001, N073) and a minimum of 2.72 cm/s (11 September 2000-9 July 2002, 
N084) (Figure 3b). The eddy Rossby number $\left(\bar{R}_{\text {eddy }}\right)$ is mostly less than 0.5 (Figure 3c). Large dispersion is found before 1995, with large values of 3.99 (N021), 3.70 (N022), and 2.76 (N024) during 17 May-10 June 1994 and 18 May-10 June 1994, and a small value of 0.03 during 7 August-30 December 1994 (N031).

Small dispersion is found after 1995, with a maximum of 0.33 during 5 May 1999-18 May 2000 (N069) (Figure 3c). The background velocity scale $\left(\bar{V}_{b}\right)$ has larger dispersion before 1995, with a maximum of $31.59 \mathrm{~cm} / \mathrm{s}$ during 19 May-10 June 1994 (N021) and a minimum of $5.33 \mathrm{~cm} / \mathrm{s}$ during 12 August-11 September 1992 (N002). It has smaller dispersion after 1995, with a maximum of $14.14 \mathrm{~cm} / \mathrm{s}$ during 21 November 1999-12 February 2001 (N075) and a minimum of $4.19 \mathrm{~cm} / \mathrm{s}$ during 29 April 1998-24 June 1999 (N065) (Figure 3d). The $E_{\text {eddy }} / E_{b}$ ratio has larger dispersion before 1995, with a maximum of 11.18 during 17 May-9 June 1994 (N024) and a minimum of 0.13 during 7 July-5 September 1993 (N007). It has smaller dispersion after 1995, with a maximum of 5.45 during 21 November 1999-12 February 2001 (N073) and a minimum of 0.23 values during 11 September 2000-9 July 2002 (N084) (Figure 3e). The three very short-lived floats (N021-N024) are responsible for most outliers (i.e., high Rossby numbers $(3.99,3.70,2.76)$, small radial scales $(1.26$, $0.90,1.41) \mathrm{km}$, and high eddy velocities $(44.17,29.22,33.94) \mathrm{cm} / \mathrm{s})$. This may indicate the existence of submesoscale eddies.

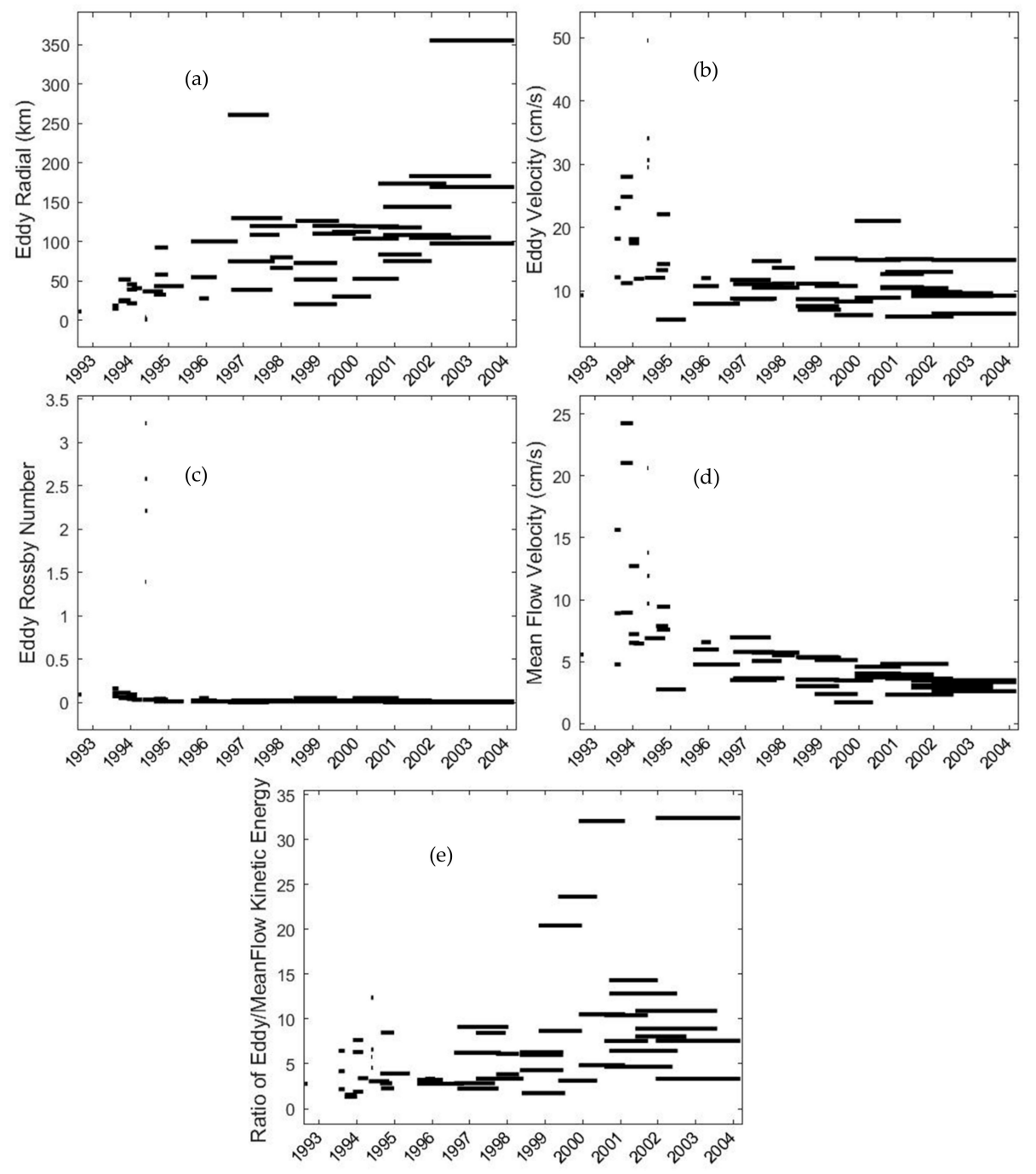

Figure 3. Temporal variation of identified current and eddy characteristic parameters $\left(\bar{L}_{e d d y}, \bar{V}_{\text {eddy }}, \bar{R}_{e d d y}, \bar{V}_{b}, \bar{r}\right)$ from 54 RAFOS floats: (a) eddy radial scale $(\mathrm{km}),(\mathbf{b})$ eddy velocity scale $(\mathrm{cm} / \mathrm{s}),(\mathbf{c})$ eddy Rossby number, (d) current velocity scale $(\mathrm{cm} / \mathrm{s})$, and (e) eddy and current kinetic energy ratio. 


\section{Conclusions}

The deterministic-stochastic EMD is used to decompose a Lagragian trajectory. Time differentiation of the deterministic and stochastic trajectories determines a Lagragian background and eddy velocities. Five parameters can be identified from single Lagrangian drifter data to represent background velocity and eddy characteristics such as the eddy radius $\left(L_{e d d y}\right)$, eddy velocity $\left(V_{\text {eddy }}\right)$, eddy Rossby number $\left(R_{\text {eddy }}\right)$, background velocity scale $\left(V_{b}\right)$, and the eddy-background kinetic energy ratio $(r)$.

The NPS RAFOS dataset consisting of 54 floats was used as an example to demonstrate the capability of the deterministic-stochastic EMD. The obtained 54 sets of parameters $\left(\bar{L}_{e d d y}, \bar{V}_{e d d y}, \bar{R}_{e d d y}, \bar{V}_{b}, \bar{r}\right)$ showed an eddy-rich area near the California coast with the mean eddy-background kinetic energy ratio of 1.78. These eddies are both cyclonic and anticylconic with a total of 186 cyclonic and 253 anticyclonic loops. The identified eddy characteristic parameters have evident temporal variabilities. Large dispersion was found in $L_{e d d y}$ before August 1998, and small dispersion in $L_{e d d y}$ was found after August 1998. However, large dispersion of $\left(V_{\text {eddy }}, R_{\text {eddy }}, V_{b}, r\right)$ was found before 1995 and small dispersion was found after 1995. Further studies on physical mechanisms that can cause such a temporal variability are needed, especially in regards to the ENSO effect, baroclinic instability, and topographic drag. These results are compatible with an earlier study on a similar dataset using more a complicated methodology [14].

Author Contributions: Conceptualization, P.C.C.; methodology, P.C.C.; software, C.F.; validation, C.F.; formal analysis, P.C.C.; investigation, C.F.; resources, P.C.C.; data curation, C.F.; writing-original draft preparation, P.C.C.; writing-review and editing, P.C.C.; visualization, C.F.; supervision, P.C.C.; project administration, P.C.C.

Funding: This research received no external funding.

Acknowledgments: The authors would like to thank Curt Collins at the Naval Postgraduate School for collecting the RAFOS data and unselfishly providing data from the website.

Conflicts of Interest: The authors declare no conflict of interest.

\section{References}

1. Chu, P.C. Steepest ascent low/non-low frequency ratio in empirical mode decomposition to separate deterministic and stochastic velocities from a single Lagrangian drifter. J. Geophys. Res. Oceans 2018, 123, 1708-1721. [CrossRef]

2. Ivanov, L.M.; Chu, P.C. Estimation of turbulent diffusion coefficients from decomposition of Lagragian trajectories. Ocean Model. 2019, 137, 114-131. [CrossRef]

3. Bauer, S.; Swenson, M.S.; Griffa, A.; Mariano, A.J.; Owens, K. Eddy-mean decomposition and eddy-diffusivity estimates in the tropical Pacific Ocean. J. Geophys. Res. Oceans 1998, 103, 30855-30871. [CrossRef]

4. Galanis, G.N.; Louka, P.; Katsafados, P.; Pytharoulis, I. Applications of Kalman filters based on non-linear functions to numerical weather predictions. Ann. Geophys. 2006, 24, 2451-2460. [CrossRef]

5. Lozano, C.J.; Robinson, A.R.; Arrango, H.G.; Gangopadhyay, A.; Sloan, Q.; Haley, P.J.; Anderson, L.; Leslie, W. An interdisciplinary ocean prediction system: Assimilation strategies and structured data models. In Modern Approaches to Data Assimilation in Ocean Modeling; Elsevier Oceanography Series; Malanotte-Rizzoli, P., Ed.; Elsevier: Amsterdam, The Netherlands, 1996; Volume 61, pp. 413-452.

6. Chu, P.C.; Ivanov, L.M.; Korzhova, T.P.; Margolina, T.M.; Melnichenko, O.M. Analysis of sparse and noisy ocean current data using flow decomposition. Part 1: Theory. J. Atmos. Ocean. Technol. 2003, 20, 478-491. [CrossRef]

7. Chu, P.C.; Ivanov, L.M.; Korzhova, T.P.; Margolina, T.M.; Melnichenko, O.M. Analysis of sparse and noisy ocean current data using flow decomposition. Part 2: Application to Eulerian and Lagrangian data. J. Atmos. Ocean. Technol. 2003, 20, 492-512. [CrossRef]

8. Chu, P.C.; Fan, C.W. Accuracy progressive calculation of Lagrangian trajectory from gridded velocity field. J. Atmos. Ocean. Technol. 2014, 31, 1615-1627. [CrossRef]

9. Huang, N.; Shen, Z.; Long, S.R.; Wu, M.C.; Smith, H.H.; Zheng, Q.; Yen, N.; Tung, C.C.; Liu, H.H. The empirical mode decomposition and the Hilbert spectrum for nonlinear and non-stationary time series analysis. Proc. R. Soc. Lond. 1998, 454, 903-995. [CrossRef] 
10. Chu, P.C.; Fan, C.W.; Huang, N. Compact empirical mode decomposition-An algorithm to reduce mode mixing, end effect, and detrend uncertainty. Adv. Adapt. Data Anal. 2012, 4, 1250017. [CrossRef]

11. Chu, P.C.; Fan, C.W.; Huang, N. Derivative-optimized empirical mode decomposition for the Hilbert-Huang transform. J. Comput. Appl. Math. 2014, 259, 57-64. [CrossRef]

12. Qiao, F.L.; Yuan, Y.L.; Deng, J.; Dai, D.J.; Song, Z.Y. Wave-turbulence interaction-induced vertical mixing and its effects in ocean and climate models. Philos. Trans. R. Soc. A 2016, 374, 20150201. [CrossRef] [PubMed]

13. Collins, C.A.; Ivanov, L.M.; Melnichenko, O.B.; Gartfield, N. California Undercurrent variability and eddy transport estimated from RAFOS float observations. J. Geophys. Res. Oceans 2004, 109. [CrossRef]

14. Collins, C.A.; Margolina, T.; Rago, T.A.; Ivanov, L.M. Looping RAFOS floats in the California Current System. Deep Sea Res. Part II Top Stud. Oceanogr. 2013, 85, 42-61. [CrossRef]

15. Naval Postgraduate School RAFOS Float Data. Available online: https://www.oc.nps.edu/npsRAFOS/HTMLS/ inventory_index.html (accessed on 23 November 2019).

(C) 2019 by the authors. Licensee MDPI, Basel, Switzerland. This article is an open access article distributed under the terms and conditions of the Creative Commons Attribution (CC BY) license (http://creativecommons.org/licenses/by/4.0/). 